\title{
PEMILIHAN LOKASI BUDI DAYA IKAN, RUMPUT LAUT, DAN TIRAM MUTIARA YANG RAMAH LINGKUNGAN DI KEPULAUAN TOGEAN, SULAWESI TENGAH
}

\author{
Utojo*), Abdul Mansyur"), Akhmad Mustafa", Hasnawi"), dan Abdul Malik Tangko")
}

\begin{abstract}
ABSTRAK
Sumber daya lahan perikanan pesisir di Sulawesi Tengah yang potensial untuk pengembangan budi daya laut berada di Teluk Tomini, namun demikian belum diperoleh data secara rinci kelayakannya. Penelitian ini bertujuan untuk menentukan kelayakan lokasi bagi pengembangan budi daya di perairan Kepulauan Togean, Kabupaten Tojo Una-Una, Sulawesi Tengah dan penelitiannya dilaksanakan dengan metode survai. Pengumpulan data sekunder meliputi data iklim, pasang surut, produksi perikanan, peta rupa bumi Indonesia kawasan Tojo Una-Una skala 1:25.000, peta citra landsat7ETM digital, dan peta navigasi (batimetri) skala 1:200.000 yang dilakukan sebelum pelaksanaan survai. Data primer diperoleh melalui pengukuran langsung di lapang yang meliputi topografi pantai, keterlindungan, oseanografi, dan biologi. Seluruh lokasi pengambilan contoh ditentukan posisinya dengan Global Positioning System (GPS) dan data yang diperoleh dianalisis dengan menggunakan Sistem Informasi Geografis (SIG). Dari hasil penelitian ini telah diidentifikasi sumber daya lahan perikanan pesisir yang potensial dikembangkan dan dinilai layak untuk kegiatan budi daya laut yaitu seluas 1.601,3 hektar. Lokasi yang potensial dikembangkan untuk budi daya ikan dalam keramba jaring apung (KJA) terdapat di sekitar Kepulauan Siatu 365,2 hektar; Kepulauan Salaka 385,8 hektar; dan Pulau Kadidiri 270,9 hektar. Sedangkan lokasi yang potensial dikembangkan untuk budi daya rumput laut dan tiram mutiara terdapat di sekitar Pulau Huo dan Bungin 579,4 hektar. Seluruh lokasi tersebut ditampilkan dalam peta prospektif skala 1:50.000.
\end{abstract}

ABSTRACT: Site selection for fish, seaweed, and pearl oysters culture in Togean Archipelago, Central Sulawesi. By: Utojo, Abdul Mansyur, Akhmad Mustafa, Hasnawi, and Abdul Malik Tangko

Central Sulawesi had coastal resources which are potential to be developed for mariculture i.e Tomini Bay, however the scientific data support was unavailable. This study was conducted by survey method to find out suitable location to be developed for mariculture in Togean Archipelago, Tojo Una-Una Regency, Central Sulawesi. Secondary data such as wheather, tidal plate, coastal fisheries production, Indonesia earth surface map of scale 1:50,000, citra land sat-7ETM digital product, and navigation map of scale 1:200,000 were collected before the study. The primary data was collected from each study areas and interpreted as mariculture requirement for several domesticated species i.e. fish, seaweed, and mollusca. Tematic map of area, suitability as the main expected out put of the study was made through spatial analysis and GIS as suggested by reference. The total potential areas which were suitable for mariculture development are 1,601.3 hectares, namely either for fish culture in floating net cage (1,021.9 hectares), seaweed and pearl oysters (579.4 hectares) were distribution in the sea waters of Siatu, Salaka, Kadidiri, Huo, and Bungin island.

KEYWORDS: natural resources, coastal, aquaculture, site selection

Peneliti pada Balai Riset Perikanan Budidaya Air Payau, Maros 


\section{PENDAHULUAN}

Dalam pemanfaatan potensi sumber daya lahan pesisir untuk pengembangan kegiatan budi daya laut di perairan Kepulauan Togean Sulawesi Tengah di masa datang memiliki prospek yang cerah dengan ekosistem sumber dayanya yang masih lestari dan belum dimanfaatkan secara optimal. Kelestarian ekosistem tersebut sangat dipengaruhi dan ditentukan oleh karakteristik wilayahnya sehingga dalam penanganannya harus secara berhati-hati, cermat, optimal, efisien, dan berkelanjutan serta disesuaikan dengan daya dukung lingkungan yang secara ekonomis menguntungkan. Potensi peningkatan produksi hasil budi daya cukup besar karena memiliki sumber daya lahan dan peluang untuk melakukan kegiatan budi daya laut cukup luas.

Di wilayah tersebut terdapat tiga faktor yang merupakan modal dasar sangat vital bagi pembangunan perikanan antara lain keragaman biologis organisme akuatik bernilai ekonomis penting, potensi lahan, dan sumber daya manusianya. Untuk itu diperlukan dukungan penelitian dan iptek yang mantap seperti kegiatan identifikasi, inventarisasi, karakterisasi potensi sumber daya lahan, komoditas, dan genetik sebagai acuan dalam strategi pemanfaatan sumber daya secara rasional untuk pengembangan budi daya laut yang ramah lingkungan (Rachmansyah et al., 1999).

Identifikasi kelayakan sumber daya lahan untuk pengembangan budi daya laut penting artinya dalam rangka penataan ruang daerah yang sesuai dengan peruntukannya sehingga menghindarkan konflik kepentingan baik antar sektor kelautan/perikanan maupun dengan sektor lain dan juga dengan pemilihan lokasi untuk budi daya laut yang tepat dapat digunakan sebagai indikator awal keberhasilan usaha budi daya sesuai dengan jenis komoditas dan teknologi budi daya yang akan diterapkan (Poernomo, 1988).

Berdasarkan program Badan Perencanaan dan Pembangunan Daerah (Bappeda) dan Dinas Kelautan dan Perikanan (Dislutkan) Provinsi Sulawesi Tengah dan Kabupaten Tojo Una-Una, wilayah pengembangan budi daya laut dipusatkan pada perairan Kepulauan Togean, Kabupaten Tojo Una-Una. Pengembangan wilayah tersebut didasarkan pada ciri-ciri lingkungan budi daya laut, potensi sumber daya hayati laut dan faktor penunjang lainnya.
Kabupaten Tojo Una-Una termasuk wilayah Provinsi Sulawesi Tengah, membujur pada posisi 0'6'56" sampai 337'41" Lintang Selatan

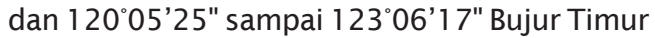
serta memiliki luas wilayah $14.433,76 \mathrm{~km}^{2}$ atau 21,22\% dari luas daratan Provinsi Sulawesi Tengah. Topografi wilayahnya merupakan daerah yang datar, berbukit, dan bergunung serta secara geografis dibatasi oleh di sebelah utara berbatasan dengan Teluk Tomini dan Provinsi Gorontalo, di sebelah selatan berbatasan dengan Provinsi Sulawesi Selatan dan Kabupaten Morowali, di sebelah timur berbatasan dengan Kabupaten Banggai, dan di sebelah barat berbatasan dengan Kabupaten Donggala.

Potensi perikanan laut untuk penangkapan di Kabupaten Tojo Una-Una seluas $56.413 \mathrm{~km}^{2}$, sedangkan sumber daya lahan budi daya laut belum ada data potensinya (Anonim, 2001; 2002). Untuk kegiatan budi daya laut yang berhasil guna dan berdaya guna, maka penentuan lokasi sesuai dengan kondisi perairan, jenis komoditi dengan metode budi daya yang tepat dan ekonomis serta dekat dengan pusat pemasaran perlu menjadi perhatian. Satu kendala utama dalam pembangunan budi daya laut di Kabupaten Tojo Una-Una yaitu ketersediaan data dan informasi lahan pengembangan budi daya laut yang belum diinventarisasikan secara lengkap sehingga berimplikasi terhadap tumpang tindihnya pemanfaatan ruang perairan baik antar sektor maupun lintas sektoral. Sehubungan dengan hal tersebut, penelitian ini bertujuan untuk menginventarisasi kelayakan lahan budi daya laut di perairan Kepulauan Togean yang disajikan dalam bentuk peta tematik. Hasil penelitian ini diharapkan menjadi masukan bagi pemerintah daerah untuk mengalokasikan pengembangan budi daya laut dalam rangka penyusunan rencana tata ruang wilayah.

\section{BAHAN DAN METODE}

Penelitian pemetaan kelayakan lahan budi daya laut dilaksanakan di Kepulauan Togean dalam kawasan perairan Teluk Tomini, Kabupaten Tojo Una-Una pada bulan Juli dan September 2003, pemilihan lokasi survai ditentukan berdasarkan program Badan Perencanaan Pembangunan Daerah dan Dinas Kelautan dan Perikanan Provinsi Sulawesi Tengah dan Kabupaten Tojo Una-Una, mengenai pengembangan wilayah perikanan pesisir untuk penerapan budi daya laut. 
Penelitian ini menggunakan metode survai yang dirancang berdasarkan Sistem Informasi Geografis (SIG). Penentuan stasiun pengamatan sebanyak 13 titik yang dilakukan dengan simple random sampling (Clark \& Hosking, 1986) dan penyebarannya dapat mewakili lokasi penelitian. Setiap titik stasiun pengamatan ditentukan posisi atau titik koordinatnya dengan alat GPS (Global Positioning System). Sebaran titik stasiun pengamatan di lokasi penelitian dapat dilihat pada Gambar 1. Sedangkan diagram alur analisis spasial pada pemetaan kelayakan lokasi lahan budi daya laut dengan menggunakan teknologi SIG disajikan pada Gambar 2.

Data yang dikumpulkan dalam penelitian ini terdiri atas data primer dan data sekunder. Data primer yang dikumpulkan adalah data kualitas perairan yang meliputi peubah fisik (ombak, arus, kedalaman, suhu air, kekeruhan, kecerahan), kimia (salinitas, $\mathrm{pH}$, fosfat, nitrat, nitrit, amonia), logam berat (timbal (Pb), kadmium (Cd), seng ( $\mathrm{Zn})$, dan tembaga (Cu), dan tekstur sedimen. Data sekunder berupa peta dasar digital lokasi penelitian. Peta dasar ini bersumber dari hasil scan dan digitasi peta rupa bumi skala 1:50.000, lembar 2215, tahun 1991 keluaran Badan Koordinasi Survai dan Pemetaan Nasional (Bakosurtanal), peta bathimetri skala 1:200.000, nomor 305, tahun 1991 keluaran Dinas Hidro-Oseanografi Angkatan Laut (Dishidros AL), dan citra satelit land sat-7ETM, tahun 2002 keluaran Lembaga Penerbangan dan Antariksa Nasional (LAPAN). Informasi dari peta dasar yang diambil meliputi garis pantai, sungai, garis batas wilayah, jalan, terumbu karang, lumpur (sedimentasi), mangrove, penggunaan lahan, sebaran penduduk, letak, dan nama lokasi, garis kontur atau ketinggian daratan dan kedalaman laut.

Kriteria yang digunakan sebagai dasar skala penilaian dan bobot pada kelayakan lahan untuk budi daya ikan, rumput laut, dan tiram mutiara, mengacu pada persyaratan yang disarankan oleh Ahmad et al. (1991); Mubarak et al. (1990); dan Atjo (1992) disajikan pada Tabel 1, 2, dan 3.

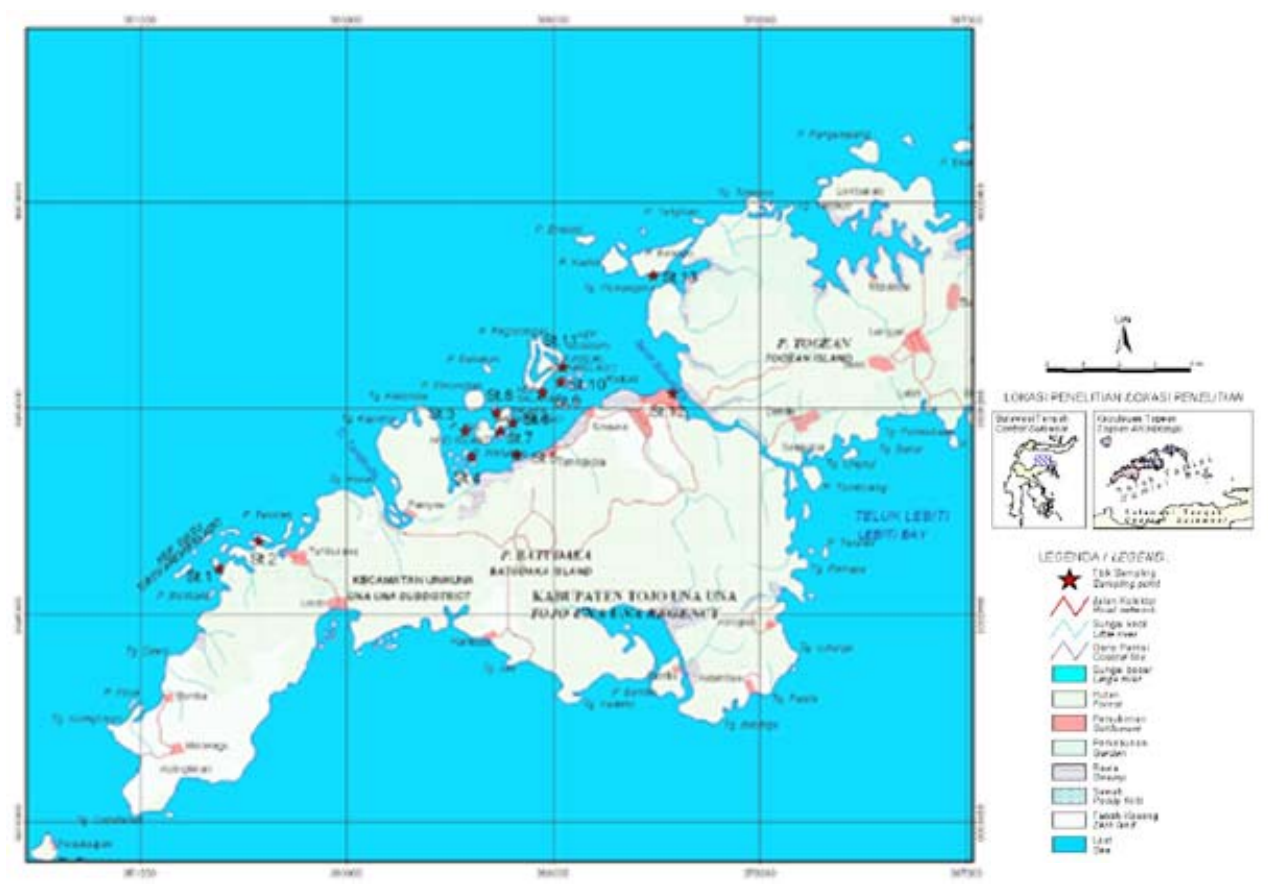

Gambar 1. Peta sebaran stasiun pengamatan kelayakan lokasi budi daya laut di Kepulauan Togean, Sulawesi Tengah

Figure 1. Map of sampling station distribution of mariculture location suitability in Togean Archipelago, Central Sulawesi 


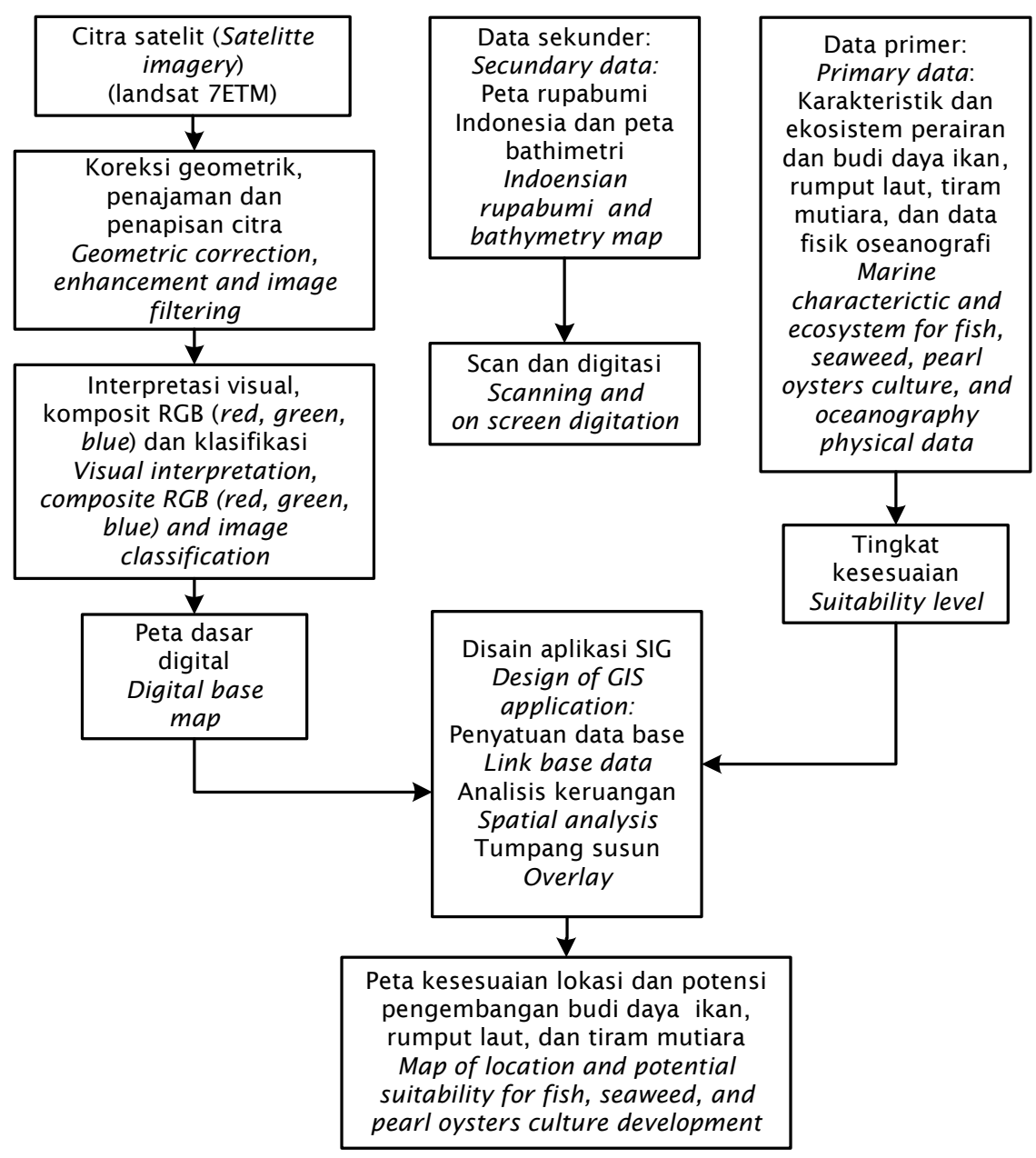

Gambar 2. Skema analisis terintegrasi SIG dan Inderaja pada pembuatan peta kelayakan wilayah pesisir untuk budi daya ikan, rumput laut, dan tiram mutiara

Figure 2. Schema of GIS integration analysis and remote sensing at the coastal area suitability mapping for fish, seaweed, and pearl oysters culture

Kelayakan lahan untuk budi daya ikan dalam KJA mengacu pada persyaratan yang disarankan (Area suitability for fish culture in the floating net cages according (Ahmad et al., 1991). Sedangkan kelayakan lahan untuk budi daya rumput laut mengacu pada persyaratan yang disarankan Area suitability for seaweed culture according (Mubarak et al., 1990)

Cara mendapatkan skala penilaian dan bobot tersebut adalah sebagai berikut: pembobotan pada setiap faktor pembatas/ peubah ditentukan berdasarkan pada dominannya peubah tersebut terhadap suatu peruntukan kelayakan lahan budi daya laut (ikan, rumput laut, dan tiram mutiara). Kemudian diurutkan faktor-faktor pembatas tersebut dimulai dari yang paling berpengaruh terhadap suatu peruntukan. Bobot terbesar ditentukan 1,00 dan terkecil 0,00 . Semua bobot berjumlah 1,00. Dengan demikian, karena jumlah faktor pembatas dalam matriks cukup banyak, maka umumnya setiap faktor tersebut mempunyai bobot berupa pecahan antara 0,00 sampai 1,00 . Untuk setiap faktor pembatas dalam kolom matriks dibuat skala penilaian dengan angka dari mulai 1 (kurang layak), 2 (cukup 


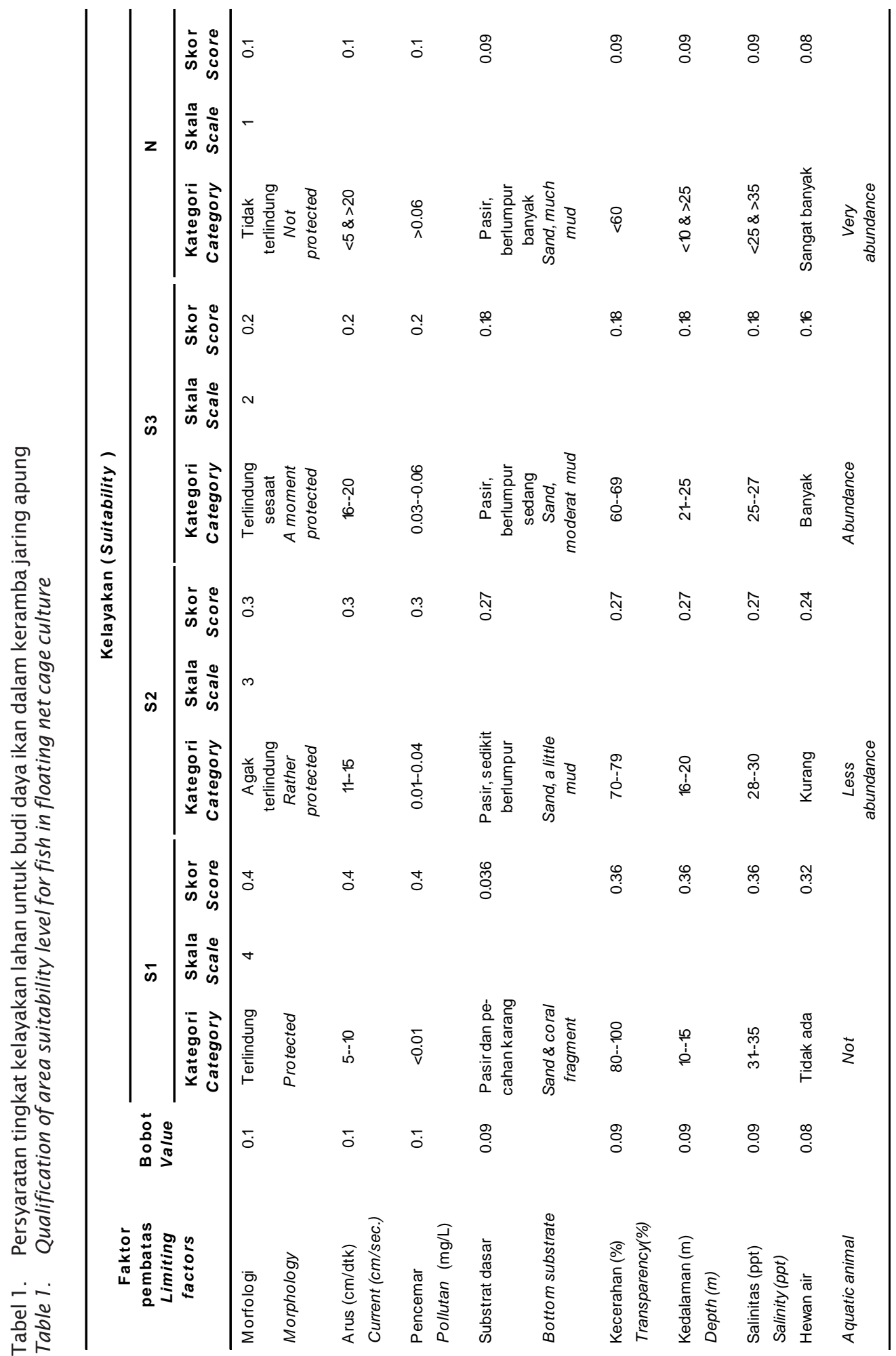




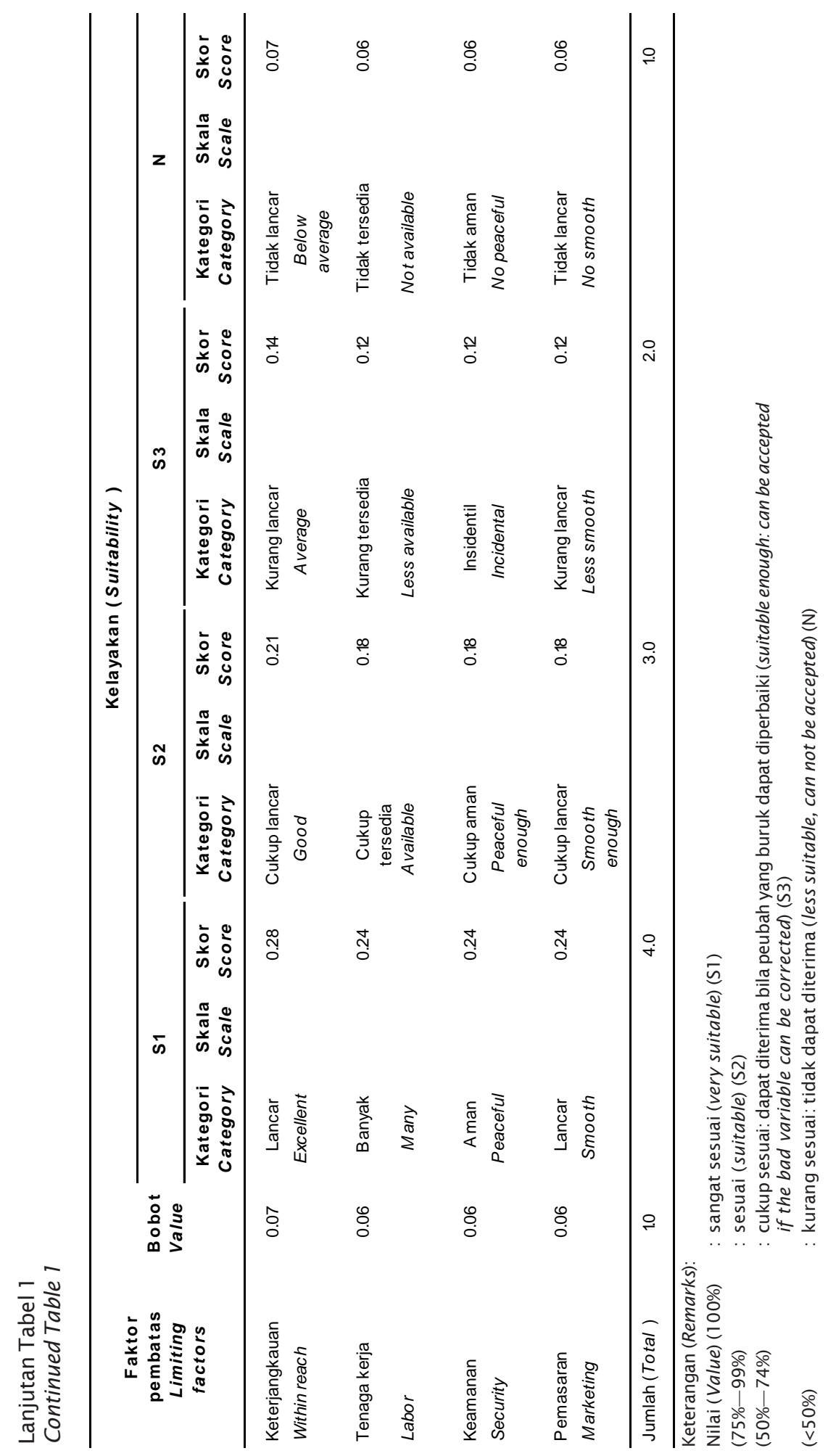




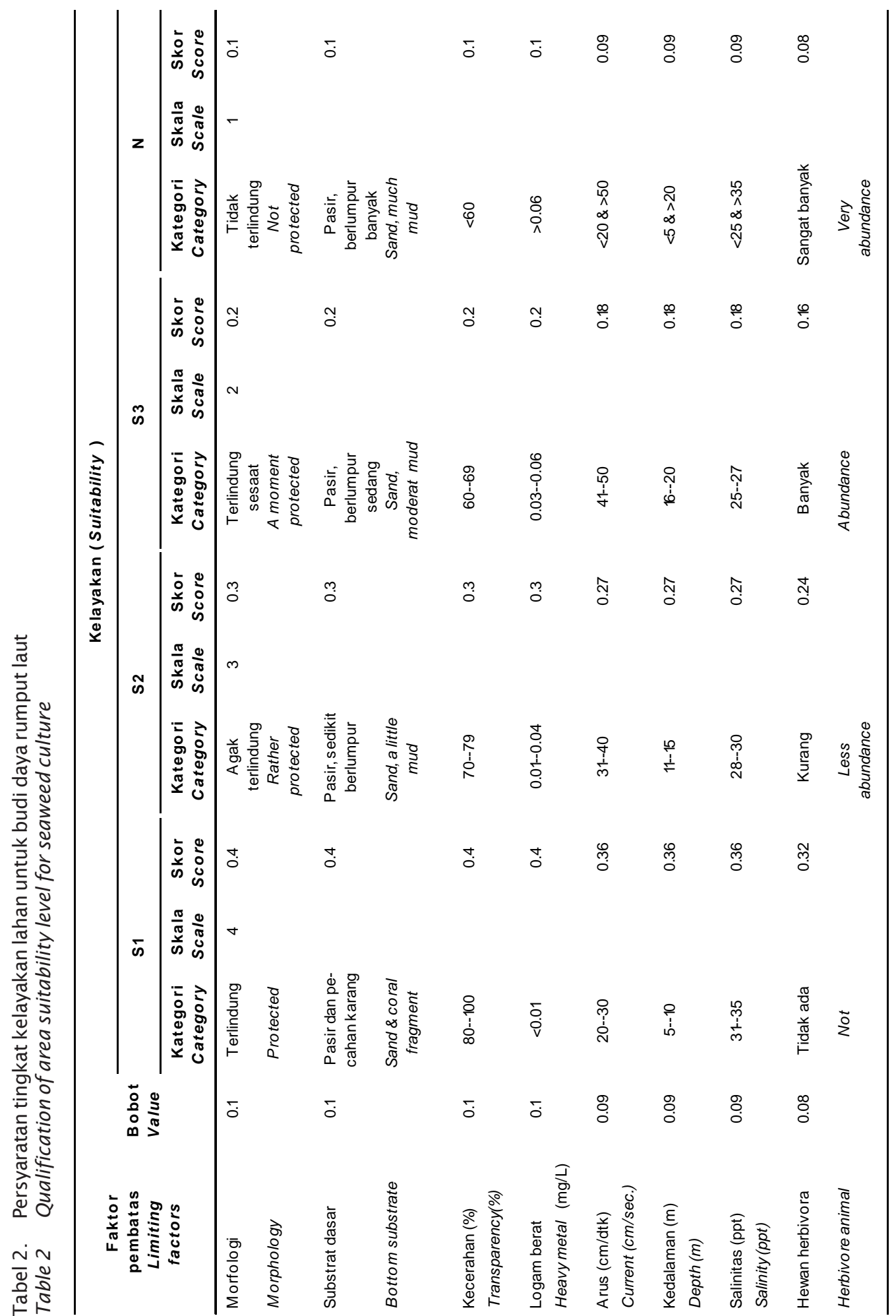




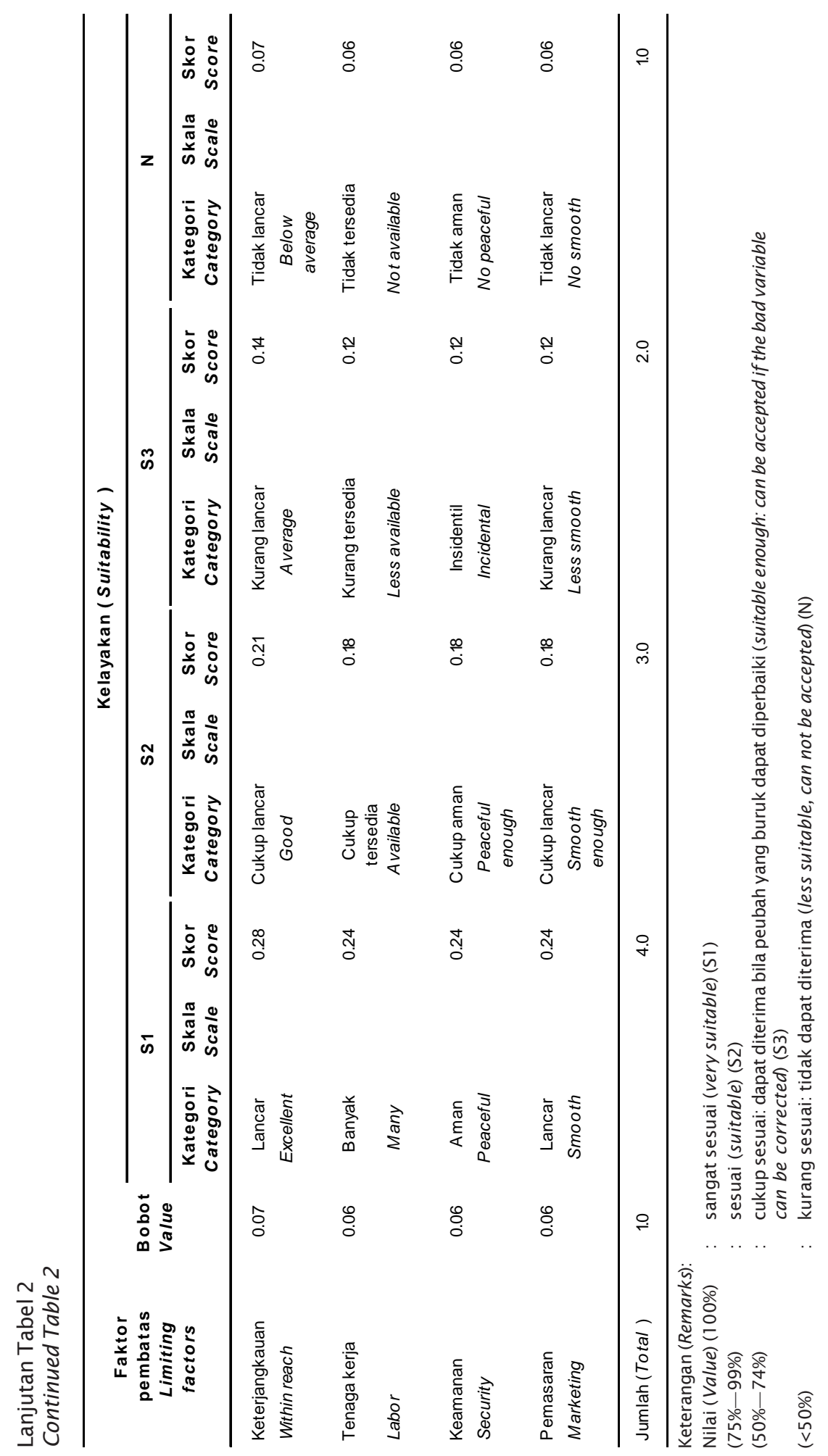




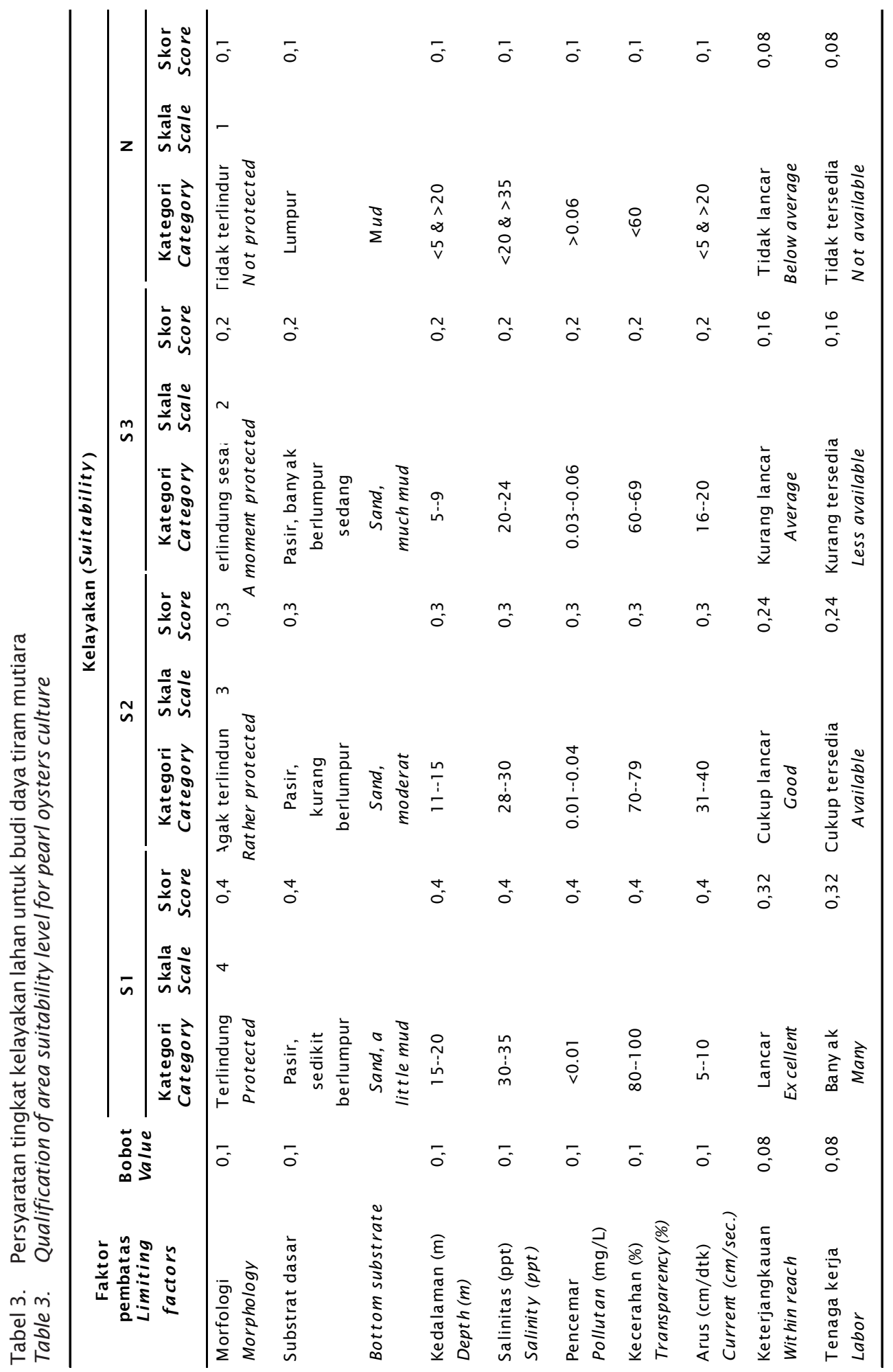




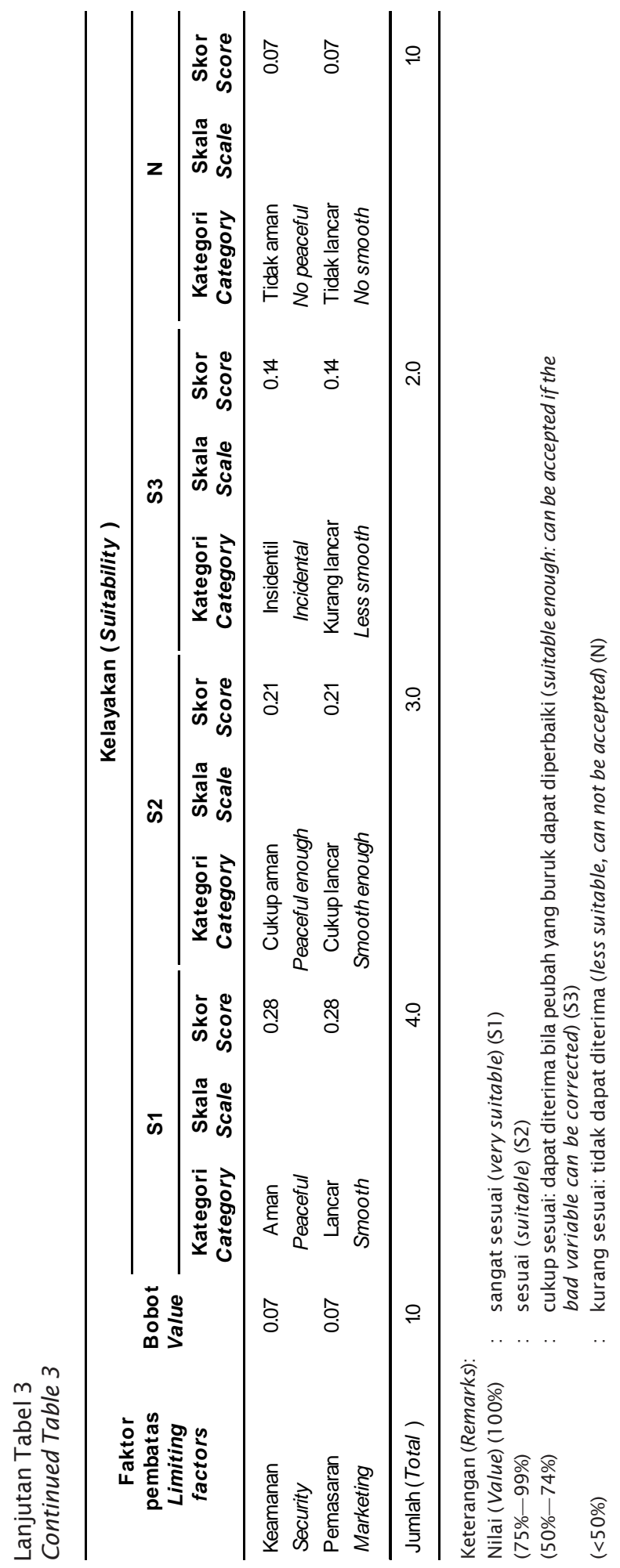


layak), 3 (layak), dan 4 (sangat layak). Kemudian dihitung perkalian bobot dengan skala penilaian untuk menentukan nilai akhir (skor) dari faktor-faktor tersebut. Kemudian dihitung skor total semua faktor pembatas dari setiap kolom skala penilaian dari mulai 1,00 (kurang layak) sampai 4,00 (sangat layak). Kisaran prosentase skala penilaian pada setiap kolom yaitu nilai 4,00 $(100 \%)=S 1$ (sangat layak); 3,00 $(75 \%-99 \%)=$ S2 $($ layak); 2,00 $(50 \%-74 \%)=$ S3 (cukup layak); 1,00 (<50\%) = N (kurang layak)

Menurut Hidayat et al. (1995), pengertian skala penilaian pada setiap kolom adalah sebagai berikut: S1 (sangat layak), apabila lahan tidak mempunyai pembatas yang berarti untuk mempertahankan tingkat pengelolaan yang harus diterapkan; S2 (layak), apabila lahan mempunyai pembatas agak berarti untuk mempertahankan tingkat pengelolaan yang harus diterapkan; S3 (cukup layak), apabila lahan mempunyai pembatas yang berarti untuk mempertahankan tingkat pengelolaan yang harus diterapkan; N (kurang layak), apabila lahan mempunyai faktor pembatas cukup berat sehingga mencegah kemungkinan penggunaannya.

Dalam menganalisis secara spasial dan Sistem Informasi Geografis (SIG) (Purwadhi et al., 1997), bertujuan untuk menentukan kesesuaian lahan budi daya laut dengan komoditas ikan, rumput laut, dan tiram mutiara. Pada proses analisis tersebut dalam program "arcview 3.3 ", data primer hasil dari setiap peubah fisik oseanografis disatukan dalam peta dasar digital dengan menginterpolasi pada setiap titik koordinat pengamatan menjadi area (polygon) menggunakan metode "Nearest Neighbor" (Morain, 1999). Dari hasil interpolasi setiap peubah fisik oseanografis yang diperoleh, kemudian disusun dalam bentuk peta tematik dengan layer-layer yang terpisah, melalui pertimbangan tingkat pembobotan dan skala penilaian, kemudian di-overlay (tumpang susun) untuk mendapatkan nilai kesesuaian lahan dan peta terkini untuk prospek peruntukan sumber daya lahan pesisir di Kepulauan Togean, bagi pengembangan budi daya laut (ikan, rumput laut, dan tiram mutiara).

\section{HASIL DAN BAHASAN}

\section{Kondisi Umum}

Kepulauan Togean terletak di bagian tengah kawasan Teluk Tomini pada koordinat $0{ }^{\circ} 21 "-0{ }^{\circ} 5^{\prime} 12^{\prime \prime}$ Lintang Selatan, $121^{\circ} 33^{\prime} 21^{\prime \prime}-122^{\circ} 23^{\prime} 36^{\prime \prime}$ Bujur Timur dengan luas wilayah $755,4 \mathrm{~km}^{2}$ dan terdiri atas 56 pulau besar dan kecil. Secara administrasi Kepulauan Togean termasuk dalam Kabupaten Tojo Una-Una. Kepulauan tersebut terbagi menjadi 2 kecamatan yaitu Kecamatan UnaUna memiliki 21 desa dan Walea Kepulauan terbagi dalam 16 desa. Perairan lautnya dikelilingi oleh formasi terumbu karang yang airnya sangat jernih sehingga dapat dilihat sampai kedalaman $30 \mathrm{~m}$. Kawasan perairan antar pulau hampir semuanya merupakan perairan dangkal dengan kedalaman maksimum 200 m (Anonim, 2003).

Kawasan penelitian ini berada di Kepulauan Togean yang terdiri atas beberapa pulau kecil seperti Pulau Siatu, Kadidiri, Salaka, Panjang, Endah, Batango, Sunsuri, Bodong, Huo, Watubalu, dan Pulau Kasojo dan letaknya saling berdekatan satu dengan lainnya sehingga lokasi tersebut potensial untuk kegiatan budi daya laut.

Di Kepulauan Togean karangnya paling unik karena diperkaya dengan padang lamun dan di sepanjang tepi pantai ditumbuhi pohon mangrove jenis Rhizopora. Perairan lautnya memiliki sekitar 115 jenis Scleractinia (karang keras) dari 59 marga karang yang lokasinya cukup berdekatan antara satu jenis dengan jenis lainnya dan umumnya terumbu karang mengelilingi pulau-pulau tersebut. Keberadaan terumbu karang dan lamun merupakan habitat ikan karang, rumput laut, dan teripang yang bernilai ekonomis tinggi, serta mempunyai potensi pengembangan budi daya tiram mutiara, rumput laut, dan teripang serta kawasan konservasi laut yang berkelanjutan (Anonim, 2003).

Potensi sumber daya alam Kepulauan Togean memiliki ciri khas tersendiri dibandingkan dengan daerah lainnya, sehingga menjadikan kawasan ini sebagai daya tarik dan menjadi incaran para pelaku usaha perikanan seperti pengusaha lokal, nasional, dan internasional.

Topografi daratan pulau-pulau yang terdapat di Kepulauan Togean mulai dari rata hingga berbukit, memiliki ekosistem hutan tropis dataran rendah yang masih asli dan ekosistem hutan bakau yang ditemui hampir di semua pulau besar.

Berdasarkan hasil pengukuran langsung dan analisis pasang surut di sekitar Kepulauan Togean menunjukkan bahwa kondisi pasang surut di lokasi penelitian tergolong tipe 
campuran yang cenderung ke harian ganda atau komponen semidiurnal yaitu terjadi dua kali air pasang dan dua kali air surut dalam sehari dengan tunggang pasang $99 \mathrm{~cm}$. Kondisi pasang surut yang demikian ini sangat mempengaruhi mutu lingkungan perairan dan luas area untuk kegiatan budi daya laut.

Saat ini di Kepulauan Togean terdapat kegiatan usaha penampungan ikan karang hidup yang bernilai ekonomis tinggi seperti kerapu macan, kerapu sunu bintik kasar dan halus, kerapu tikus, kerapu lumpur, dan napoleon serta teripang, yang tersebar di Pulau Siatu, Panjang, Endah, Kasojo, Kadidiri, dan Bodong. Usaha tersebut dikelola oleh 5 pengusaha lokal. Sedangkan di sekitar Pulau Huo dan Watubalu juga terdapat kegiatan budi daya tiram mutiara dan industri mutiara buatan yang dikelola pengusaha asing.

Skala usaha berupa kepemilikan keramba oleh pengusaha penampungan ikan di Kepulauan Togean sudah cukup memadai. Kepemilikan rakit bervariasi antara $1-10$ unit dengan 4-6 buah jaring ukuran $3 \mathrm{~m} \times 3 \mathrm{~m} \times 3$ $\mathrm{m}$ dan $4 \mathrm{~m} \times 4 \mathrm{~m} \times 4 \mathrm{~m}$. Produktivitas usaha penampungan berfluktuasi karena volume produksi sangat tergantung dari hasil tangkapan nelayan. Masa penampungan relatif singkat antara $1-2$ bulan, tergantung dari ukuran dan jenis ikan yang didapatkan seperti ikan sunu bintik halus dan kasar serta kerapu tikus yang memiliki ukuran ekspor dan harganya mahal, sehingga walaupun terkadang sedikit yang diperoleh dari nelayan, namun usaha penampungan tetap saja beroperasi karena secara ekonomis masih menguntungkan. Produksi ikan hidup setiap bulan dari usaha penampungan ini sangat bervariasi antara $200-2.000 \mathrm{~kg}$ tergantung musim, ukuran dan jenis ikan dengan pemasaran utama Hongkong dan Singapura.

Aspek penunjang lain terdapat tempat pendaratan ikan dan transportasi penumpang dengan kapal motor dari Kecamatan Wakai, Pulau Batudaka, Togean, Una-una ke Kecamatan Ampana Kabupaten Tojo Una-Una.

\section{Kondisi Perairan}

Berdasarkan hasil survai kualitas lingkungan perairan Kepulauan Togean di 13 titik pengamatan dan pengambilan contoh air serta sedimen dasar pada pukul 09.15-16.45 WITA, secara umum masih dalam batas toleran untuk kegiatan budi daya laut (ikan dalam keramba jaring apung, rumput laut, dan tiram mutiara). Kisaran data kualitas perairan hasil pengamatan disajikan pada Tabel 4.

Dari hasil pengukuran peubah fisik dan kimia perairan menunjukkan bahwa perairan di lokasi penelitian masih sangat baik untuk kegiatan budi daya laut. Tinggi ombak dan kecepatan arus di perairan Kepulauan Togean berkisar $6-35 \mathrm{~cm}$ dan 0,036-0,184 m/detik. Kisaran nilai tersebut masih dalam kategori baik untuk kegiatan budi daya laut. Kedalaman perairan yang merupakan hasil penggabungan data kedalaman dari pengukuran lapangan dan data bathimetri Dishidros berkisar 4,2-20,9 $\mathrm{m}$. Kedalaman air dipengaruhi oleh perubahan pasang dan kontur dasar perairan serta sangat berperan dalam menentukan metode budi daya laut. Menurut Ahmad et al. (1991), kedalaman ideal perairan pada saat surut terendah antara keramba jaring apung (KJA) dengan dasar perairan minimal $5 \mathrm{~m}$. Hal ini memberikan ruang terjadinya pertukaran nutrien atau limbah sisa KJA, sedangkan menurut Mubarak et al. (1990) untuk budi daya rumput laut dengan metode rakit terapung kedalaman ideal perairan pada saat surut terendah antara rakit dengan dasar perairan minimal $5 \mathrm{~m}$ dengan substrat dasar pasir, pecahan karang dan sedikit lumpur. Menurut Atjo (1992), untuk budi daya tiram mutiara dengan metode rakit terapung kedalaman air yang optimal adalah $10 \mathrm{~m}$. Hal ini disebabkan untuk menghindari adanya distribusi sedimentasi dari dasar perairan.

Suhu air dengan kisaran $29,9^{\circ} \mathrm{C}-30,6^{\circ} \mathrm{C}$ masih tergolong dalam kategori baik untuk budi daya laut. Seperti yang dikemukakan oleh Mayunar et al. (1995) bahwa suhu air untuk kegiatan budi daya ikan yaitu $27^{\circ} \mathrm{C}-32^{\circ} \mathrm{C}$, sedangkan untuk budi daya rumput laut kisaran suhu yang baik $20^{\circ} \mathrm{C}-28^{\circ} \mathrm{C}$ (Mubarak et al., 1990). Suhu air yang baik untuk kegiatan budi daya tiram mutiara $20^{\circ} \mathrm{C}-32^{\circ} \mathrm{C}$ (Atjo, 1992). Kecerahan perairan masih dalam kategori yang baik untuk budi daya laut yaitu berkisar $85,6 \%-$ 100\% (> 5m). Menurut Ahmad et al. (1991), kecerahan air yang baik untuk budi daya ikan lebih dari $3 \mathrm{~m}$, sedangkan untuk budi daya rumput laut kecerahan air yang baik minimal 5 m (Mubarak et al., 1990). Menurut Atjo (1992), kecerahan air yang baik untuk budi daya tiram mutiara lebih dari $5 \mathrm{~m}$.

Salinitas perairan berkisar $34-35 \mathrm{ppt}$ tergolong masih baik untuk kegiatan budi daya laut. Kisaran salinitas tersebut masih baik untuk kegiatan budi daya rumput laut dan tiram mutiara, sedangkan untuk kegiatan budi daya 
ikan dalam KJA, kisaran salinitas yang baik tergantung dari ikan yang akan dibudidayakan. Kandungan oksigen terlarut (DO) dalam perairan sangat penting bagi kelangsungan hidup biota laut. Hasil pengukuran menunjukkan bahwa DO berkisar 4,6-9,6 mg/ $L$ yang berarti masih dalam kisaran yang baik untuk kegiatan budi daya ikan dalam KJA, rumput laut, dan tiram mutiara sesuai yang diinginkan oleh KLH (2004) yaitu untuk kegiatan budi daya laut kandungan DO yang diinginkan adalah $>5 \mathrm{mg} / \mathrm{L}$.

Tabel 4. Hasil pengukuran fisik dan mutu air Kepulauan Togean, Sulawesi Tengah

Table 4. Result of physical and water quality measurment of Togean Archipelago, Central Sulawesi

\begin{tabular}{|c|c|c|c|}
\hline $\begin{array}{c}\text { Peubah fisik dan mut u air } \\
\text { Physical variables and } \\
\text { water quality }\end{array}$ & $\begin{array}{l}\text { Sat uan } \\
\text { Unit }\end{array}$ & $\begin{array}{l}\text { Kisaran nilai } \\
\text { Value range }\end{array}$ & $\begin{array}{l}\text { Nilai ideal } \\
\text { Ideal value }\end{array}$ \\
\hline Tinggi ombak (Wave hight) & $\mathrm{cm}$ & $6.0--35.0$ & $<50$ \\
\hline Kecepatan arus (Current) & $\mathrm{m} /$ detik & $0.036-0.184$ & $\begin{array}{l}\text { 5--10 lkan dan tiram mutiara } \\
\text { (Fish and pearl oysters) } \\
20--30 \text { Rumput laut } \\
\text { (Seaweed) }\end{array}$ \\
\hline Pasang surut (Tide) & $\mathrm{cm}$ & 99 & - \\
\hline \multirow[t]{2}{*}{ Kedalaman (Depth) } & $\mathrm{m}$ & $4.2--20.9$ & $\begin{array}{l}\text { 10--20 lkan dan tiram mutiara } \\
\text { (Fish and pearl oysters) }\end{array}$ \\
\hline & & & $\begin{array}{l}\text { 5--10 Rumput laut } \\
\text { (Seaweed) }\end{array}$ \\
\hline Substrat (Substrate): & $\%$ & $\begin{array}{l}\text { Liat be rpasir dan } \\
\text { pecahan karang } \\
\text { Sandy clay and } \\
\text { coral rubble }\end{array}$ & $\begin{array}{l}\text { Pasir dan pecahan karang } \\
\text { (Sand and coral rubble) }\end{array}$ \\
\hline Pasir (Sand) & ${ }^{\circ} \mathrm{C}$ & $55-82$ & - \\
\hline Liat (Clay) & ppt & 0--10 & - \\
\hline Debu (Silt) & NTU & $17--35$ & - \\
\hline Pecahan karang (Coral rubble) & $\%$ & 100 & - \\
\hline $\mathrm{pH}$ & & $8.1-8.3$ & $7.5-8.5$ \\
\hline Suhu (Temperature) & $\mathrm{mg} / \mathrm{L}$ & $29.9-30.6$ & $27--32$ \\
\hline Salinitas (Salinity) & ppt & $34-35$ & $30--35$ \\
\hline Kekeruhan (Turbidity) & ppt & $0-5.3$ & $<5$ \\
\hline Kecerahan (Transparency) & $\mathrm{mg} / \mathrm{L}$ & $85.6-100$ & $80-100(>5 \mathrm{~m})$ \\
\hline \multicolumn{4}{|l|}{ Dissolved oxygen } \\
\hline $\mathrm{NH}_{3}-\mathrm{N}$ & & $0.0056--0.2199$ & 0,3 \\
\hline $\mathrm{NO}_{2}-\mathrm{N}$ & & $0.0013--0.0082$ & $<0.1$ \\
\hline $\mathrm{NO}_{3}-\mathrm{N}$ & & $0.0041--0.0076$ & 0,008 \\
\hline $\mathrm{PO}_{4}^{-\mathrm{P}}$ & & 0.0057--0.0185 & 0,015 \\
\hline \multicolumn{4}{|l|}{ Logam berat (Heavy metal): } \\
\hline Kadmium (Cadmium) (Cd) & & $0.0001--0.0045$ & 0,001 \\
\hline Tembaga (Cuprum) $(\mathrm{Cu})$ & & $0.0035--0.0057$ & 0,008 \\
\hline Timbal (Plumbum ) (Pb) & & $0.0011--0.0099$ & 0,008 \\
\hline Seng $(\operatorname{Zinc})(Z n)$ & & $0.0087--0.0518$ & 0,05 \\
\hline
\end{tabular}


Di Pulau Una-Una terdapat gunung api yang saat ini keberadaan limbahnya belum berpengaruh terhadap perairan dan secara alamiah, unsur-unsur logam berat terdapat dimana-mana dalam konsentrasi yang sangat rendah. Konsentrasi tersebut akan meningkat sejalan dengan bertambahnya kegiatan manusia seperti perindustrian, pertambangan, pemukiman dan buangan lainnya yang banyak mengandung logam berat. Limbah-limbah ini dapat terakumulasi di dalam badan komoditas budi daya, di lingkungan dan dasar perairan. Hasil analisis logam berat yang terlarut dalam air di lokasi penelitian untuk kadmium (Cd) berkisar $0,0001-0,0045 \mathrm{mg} / \mathrm{L}$, tembaga $(\mathrm{Cu})$ 0,0035-0,0057 mg/L, timbal (Pb) 0,0011 0,0099 mg/L, dan seng (Zn) 0,0087-0,0518 $\mathrm{mg} / \mathrm{L}$ menunjukkan masih dalam kisaran aman dan memenuhi syarat untuk kegiatan budi daya biota laut sesuai dengan saran KLH (2004) yaitu baku mutu kadmium (Cd) $0,001 \mathrm{mg} / \mathrm{L}$; tembaga (Cu) 0,008 mg/L; seng (Zn) 0,05 mg/ $\mathrm{L}$; dan timbal $(\mathrm{Pb}) 0,008 \mathrm{mg} / \mathrm{L}$. Hasil analisis amonia, nitrit, nitrat, dan fosfat dalam air memiliki konsentrasi yang rendah dan masih dalam kisaran yang baik untuk kegiatan budi daya biota laut sesuai dengan saran $\mathrm{KLH}$ (2004).

Hasil analisis tekstur substrat dasar perairan di lokasi penelitian terdiri dari persentasi pasir berkisar $55 \%-82 \%$, lempung (0\%-10\%), debu (17\%-35\%), dan pecahan karang (100\%). Hal ini menunjukkan jenis sedimen substrat dasar perairan didominasi oleh pecahan karang, pasir berlempung dan lempung berpasir. Data tersebut sangat penting dalam perencanaan penempatan dan rancang bangun KJA dan rakit terutama untuk tipe jangkar yang akan dipakai. Selain berpengaruh terhadap kemudahan pemasangan fasilitas budi daya, juga dapat berpengaruh terhadap produktivitas perairan, kekeruhan, dan sedimentasi. Jenis dan kelimpahan plankton sangat penting sebagai indikator kesuburan perairan dalam kaitannya dengan kegiatan budi daya tiram mutiara. Kelimpahan plankton yang cukup merupakan sumber pakan alami yang baik bagi tiram mutiara yang dibudidayakan, jika kelimpahan plankton sampai melebihi batas (blooming) harus dihindari karena akan terjadi eutrifikasi yang mencirikan terjadinya pencemaran biologi. Dari hasil pengamatan didapatkan 1519 jenis plankton dengan kelimpahan berkisar 20-1.780 ind./mL. Jenis plankton yang dominan antara Iain Chaetoceros sp.,
Oscillatoria sp., Nitzschia sp., dan Scolecithrix sp. Indeks keragaman dan indeks dominansi plankton adalah 0,85-1,42 dan 0,08-0,35. Beberapa jenis fitoplankton yang potensial menyebabkan terjadinya pencemaran biologi apabila populasinya meningkat pesat yaitu Noctiluca sp., Ceratium sp., Dinophysis sp., dan Peridinium sp. (Adnan, 1984).

\section{Lokasi Pengembangan Budi Daya Laut}

Dari hasil penilaian tingkat kelayakan lokasi budi daya laut (ikan, rumput laut, dan tiram mutiara) di perairan Kepulauan Togean menunjukkan bahwa sumber daya lahan perikanan pesisir yang potensial dikembangkan untuk budi daya laut seluas 1.601,3 hektar (Gambar 3).

Lokasi yang potensial dikembangkan untuk budi daya ikan dalam KJA terdapat di sekitar Kepulauan Siatu seluas 365,2 hektar; Kepulauan Salaka dan Sunsuri seluas 385,8 hektar; dan Pulau Batango seluas 270,9 hektar. Lokasi yang potensial dikembangkan untuk budi daya rumput laut atau tiram mutiara menggunakan metode rakit atau long line terdapat di sekitar Pulau Huo dan Pulau Watubalu seluas 579,4 hektar.

Untuk pengembangan usaha budi daya laut yang ramah lingkungan dan berkelanjutan, maka potensi yang ada sebaiknya tidak dimanfaatkan seluruhnya, tetapi harus disediakan untuk kawasan penyangga dan aktivitas perikanan lainnya. Sehingga dalam kegiatan budi daya laut selanjutnya efek penurunan kualitas lingkungan perairan dapat diminimalkan. Perairan Kepulauan Togean dengan luasan potensial untuk budi daya ikan dalam KJA 1.021,9 hektar hanya dapat dimanfaatkan sebesar $10 \%$ yaitu seluas 100 hektar (Hanafi et al., 2001). Dengan pertimbangan bahwa setiap hektar lahan budi daya ikan dalam KJA dapat ditempatkan rakit secara efektif sebanyak 40 unit dan setiap rakitnya terdiri atas 4 unit keramba berukuran 2,5 m x 2,5 m x 3,5 m (Imanto et al., 1995), maka jumlah keramba yang dapat dioperasionalkan di lokasi pengembangan kawasan budi daya mencapai 4.000 unit KJA. Dengan luasan potensial 579,4 hektar untuk budi daya rumput laut atau tiram mutiara dapat dimanfaatkan hanya 58 hektar, dengan pertimbangan bahwa setiap hektar lahan budi daya rumput laut atau tiram mutiara dapat ditempatkan rakit secara efektif sebanyak 20 unit yang setiap rakitnya untuk budi daya 

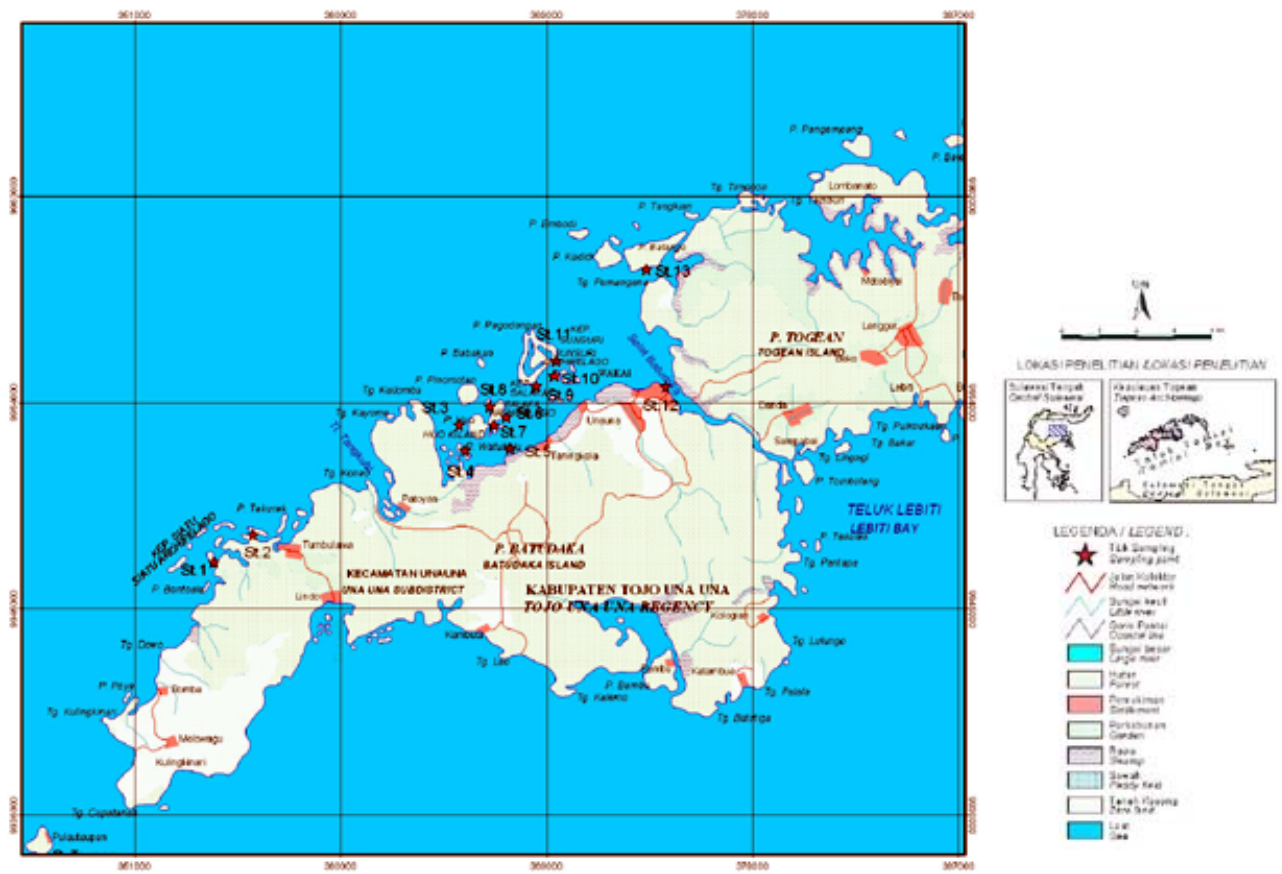

Gambar 3. Peta kelayakan lahan budi daya laut di Kepulauan Togean, Sulawesi Tengah Figure 3. Map of suitable area for mariculture in Togean Archipelago, Central Sulawesi

rumput laut berukuran $5 \mathrm{~m} \times 2,5 \mathrm{~m}$ dan untuk budi daya tiram mutiara berukuran $4 \mathrm{~m} \times 4 \mathrm{~m}$ (Mubarak et al., 1990; Atjo, 1992), maka jumlah rakit yang dapat dioperasionalkan di lokasi pengembangan kawasan budi daya mencapai 1.160 unit. Metode rakit umumnya diterapkan pada lokasi yang cukup terlindung, sedangkan metode long line diterapkan pada lokasi yang agak terbuka.

\section{KESIMPULAN}

Sumber daya lahan perikanan pesisir di perairan Kepulauan Togean, yang potensial dikembangkan untuk budi daya laut seluas $1.601,3$ hektar. Penilaian sumber daya lahan tersebut tergolong layak untuk lokasi budi daya ikan dalam KJA, budi daya rumput laut, dan tiram mutiara dengan metode rakit atau long line. Kondisi oseanografi perairan lautnya sebagai media budi daya masih layak, aman, dan mendukung kegiatan budi daya.

\section{DAFTAR PUSTAKA}

Adnan, Q. 1984. Distribution of Dinoflagellates at Jakarta Bay, Taman Jaya Ancol, Banten and Benoa Bay, Bali: A Report of an Inci- dent of Fish Poisoning at Eastern Nusa Tenggara in Toxic Red Tides and Shellfish Toxicity in Southeast Asia. Proceeding of a Consultative Meeting held in Singapore 11 14 September 1984. p. 25-27.

Ahmad, T., P.T. Imanto, Muchari, A. Basyarie, P. Sunyoto, B. Slamet, Mayunar, R. Purba, S. Diana, S. Redjeki, A.S. Pranowo, dan S. Murtiningsih. 1991. Operasional pembesaran ikan kerapu dalam keramba jaring apung. Laporan Teknis Balai Penelitian Perikanan Budidaya Pantai, Maros. 59 pp.

Anonim. 2001. Sulawesi Tengah dalam Angka (Central Sulawesi in Figures). Kerjasama Badan Pusat Statistik (BPS) Propinsi Sulawesi Tengah dengan Badan Perencanaan dan Pembangunan Daerah (BAPPEDA) Propinsi Sulawesi Tengah. 325 pp.

Anonim. 2002. Laporan Tahunan Dinas Perikanan dan Kelautan Propinsi Sulawesi Tengah Tahun 2002. Dinas Perikanan dan Kelautan Propinsi Sulawesi Tengah di Palu. $42 \mathrm{pp}$. 
Anonim. 2003. Ekosistem dan konservasi serta wisata bahari Kepulauan Togean. Dalam Burhanuddin, S., A. Supangat, B. Sulistiyo, T. Rameyo, C.R. Kepel (Eds.). Profil Sumberdaya Kelautan dan Perikanan Teluk Tomini. Badan Riset Kelautan dan Perikanan. Departemen Kelautan dan Perikanan, Jakarta. p. 58-67.

Atjo, H. 1992. Potensi sumberdaya kekerangan Kabupaten Barru. Dalam Mansur, H., Rachmansyah, A. Mustafa, dan A.M. Pirzan (Eds.). Prosiding Temu Karya Ilmiah Potensi Sumberdaya Kekerangan Sulawesi Selatan dan Sulawesi Tenggara. Watampone. (7): 810.

Clark, W.A.V. and P.L. Hosking. 1986. Statistical Methods for Geographers. John Wiley \& Sons, Inc., 513 pp.

Hidayat, A., M. Soekardi, dan Ponidi. 1995. Kajian kesesuaian lahan untuk mendukung pembangunan perikanan pantai dan pertanian di daratan Kasipute-Lainea, Sulawesi Tenggara. Dalam Laporan Akhir Hasil Penelitian Potensi dan Hasil Kesesuaian Lahan untuk Pengembangan Perikanan Pantai (Tingkat Tinjau Mendalam) Daerah Kasipute-Lainea, Sulawesi Tenggara. Pusat Penelitian Tanah dan Agroklimat Bekerjasama dengan Proyek Pembinaan Kelembagaan Penelitian Pertanian Nasional, Jakarta. p. 96-162.

Hanafi, A., Tarunamulia, A. Rachman, dan T. Ahmad. 2001. Penataan ruang Teluk Pegametan di Kecamatan Gerokgak, Bali untuk pengembangan sea farming. Dalam Sudradjat et al. Teknologi Budidaya Laut dan Pengembangan Sea Farming di Indonesia. Puslitbang Eksplorasi Laut dan Perikanan, Jakarta. p. 57-69.

Imanto, P.T., N. Listyanto, dan B. Priono. 1995. Disain dan konstruksi keramba jaring apung untuk budidaya ikan laut. Dalam Sudradjat, A., W. Ismail, B. Priono, Murniyati, dan E. Pratiwi (Eds.). Prosiding Temu Usaha Pemasyarakatan Teknologi Keramba Jaring Apung bagi Budidaya Laut. Puslitbang Perikanan, Badan Litbang Pertanian, Jakarta. p. 216-230.
KLH. 2004. Keputusan Menteri Negara Lingkungan Hidup No. 51 Tahun 2004, Tanggal 8 April 2004 tentang Baku Mutu Air Laut. Kementerian Lingkungan Hidup, Jakarta, 11 pp.

Morain, S. 1999. GIS Solution in Natural Resource Management: Balancing the Technical-Political Equation. OnWord Press, USA. $361 \mathrm{pp}$.

Mayunar, R. Purba, dan P.T. Imanto. 1995. Pemilihan lokasi untuk usaha budidaya ikan laut. Dalam Sudradjat, A., W. Ismail, B. Priono, Murniyati dan E. Pratiwi (Eds.). Prosiding Temu Usaha Pemasyarakatan Teknologi Keramba Jaring Apung bagi Budidaya Laut. Puslitbang Perikanan. Badan Litbang Pertanian, Jakarta. p. 179189.

Mubarak, H., S. Ilyas, I.S. Wahyuni, S.H. Hartati, E. Pratiwi, Z. Jangkaru, dan A. Arifudin. 1990. Petunjuk Teknis Budidaya Rumput Laut. Badan Penelitian dan Pengembangan Pertanian, Pusat penelitian dan Pengembangan Perikanan, IDRC, Infish., 93 pp.

Poernomo, A. 1988. Pembuatan Tambak Udang di Indonesia. Seri Pengembangan No. 7, 1988. Departemen Pertanian, Badan Penelitian dan Pengembangan Pertanian, Balai Penelitian Perikanan Budidaya Pantai, Maros, $30 \mathrm{pp}$.

Purwadhi, S. Hardiyanti, Susanto, dan Hidayat. 1997. Penggunaan data inderaja satelit dan sistem informasi geografis (SIG) untuk perencanaan dan pengelolaan tata ruang wilayah. Makalah dipresentasikan dalam Seminar Open House LAPAN dalam Rangka Tahun Kebangkitan IPTEK Nasional. Jakarta. 5-7 Agustus 1997. $21 \mathrm{pp}$.

Rachmansyah, Usman, dan T. Ahmad. 1999. Ketersediaan teknologi budidaya laut dalam mendukung program peningkatan ekspor hasil perikanan. Rapat Kerja Teknis dan Pembahasan Hasil-Hasil Penelitian Tahun Anggaran 1998/1999. Balai Penelitian Perikanan Pantai, Bogor, 16-17 Maret 1999. Balai Penelitian Perikanan Pantai (Unpublish). 19 pp. 